\title{
Basic Science Research
}

\section{Effect of Heat Treatment on Fracture Toughness $\left(K_{\mathrm{IC}}\right)$ and Microstructure of a Fluorcanasite-Based Glass-Ceramic}

\author{
Won-suck Oh, DDS, MS, ${ }^{1}$ Nai-Zheng Zhang, MSc, ${ }^{2}$ \\ and Kenneth J. Anusavice, DMD, $P h D^{3}$
}

\begin{abstract}
Purpose: The purpose of this study was to test the hypothesis that the increase in fracture toughness of a fluorcanasite-based glass-ceramic is a linear function of crystal volume fraction.

Materials and Methods: A total of 60 specimen bars $\left(20 \times 5 \times 2 \mathrm{~mm}^{3}\right)$ were cut from parent glass blocks, polished, annealed, randomly divided into six groups, nucleated at $680^{\circ} \mathrm{C} / 4 \mathrm{hr}$, and crystallized at the following temperatures and times: (1) $850^{\circ} \mathrm{C} / 0.5 \mathrm{hr},(2) 850^{\circ} \mathrm{C} / 1 \mathrm{hr},(3) 850^{\circ} \mathrm{C} / 3 \mathrm{hr},(4) 750^{\circ} \mathrm{C} / 6$ $\mathrm{hr},(5) 800^{\circ} \mathrm{C} / 6 \mathrm{hr}$, or $(6) 850^{\circ} \mathrm{C} / 6 \mathrm{hr}$. Indentation flaws were produced by a microhardness indenter at the center of one surface, and the prepared specimens were subjected to three-point flexure loading with the severely flawed surface under tension at a crosshead speed of $0.5 \mathrm{~mm} / \mathrm{min}$. Flexural strength and fracture toughness $\left(K_{\mathrm{IC}}\right)$ were calculated based on the indentation-strength technique. Crystal volume fraction $\left(V_{c}\right)$ was determined by quantitative stereology of scanning electron images of each group of ceramic specimens. Statistical analysis was performed using ANOVA and Duncan's multiple comparison test $(\alpha=0.05)$.

Results: The mean $K_{\mathrm{IC}}$ and $V_{\mathrm{c}}$ values ranged from 2.7 to $3.9 \mathrm{MPa} \mathrm{m}^{1 / 2}$ and $37 \%$ to $71 \%$ within the crystallization temperature range of 750 to $850^{\circ} \mathrm{C}$. Five statistical subsets of groups $1,2 / 4,3,5$, and 6 were determined as a function of crystallization temperature and holding time (Duncan's multiple comparison analysis; $\alpha=0.05)$. The lowest and highest $K_{\mathrm{IC}}$ and $V_{\mathrm{c}}$ values were associated with Groups $1\left(850^{\circ} \mathrm{C} / 0.5 \mathrm{hr}\right)$ and $6\left(850^{\circ} \mathrm{C} / 6 \mathrm{hr}\right)$, respectively. Fracture toughness increased linearly as a function of crystal volume fraction (correlation coefficient $R^{2}=0.67$ ). The fracture toughness increased by $45 \%$ when the crystal volume fraction increased by $92 \%$.

Conclusions: Mean $K_{\mathrm{IC}}$ values increased as a linear function of crystal volume fraction in a fluorcanasite-based glass-ceramic within the crystallization temperature range of 750 to $850^{\circ} \mathrm{C}$ and at isothermal crystallization time range of 0.5 to 6 hours. The control of crystallization temperature and isothermal holding time should be optimized to generate tougher, more reliable ceramic prostheses in the shortest period of time.
\end{abstract}

J Prosthodont 2007;16:439-444. Copyright @ 2007 by The American College of Prosthodontists.

INDEX WORDS: fluorcanasite-based glass-ceramic, nucleation and crystallization process, fracture toughness, crystal volume fraction

$\mathrm{F}$ OR a glass-ceramic to be an alternative to a metal-ceramic system, the ceramic shouldprovide a comparable or greater resistance to fracture. ${ }^{1,2}$ One measure of fracture resistance is

${ }^{1}$ Associate Clinical Professor, Division of Prosthodontics, Department of Biologic \& Materials Sciences, University of Michigan School of Dentistry, Ann Arbor, MI.

Department of Biomaterials, University of Florida College of Dentistry, Gainesville, FL:

${ }^{2}$ Chemist.

${ }^{3}$ Professor and Associate Dean.

Accepted June 14, 2006.

Correspondence to: Won-Suck Oh, University of Michigan School of Dentistry, 1011 N. University, Ann Arbor, MI 48109-1078. E-mail: ohws@umich.edu

Copyright $₫ 2007$ by The American College of Prosthodontists 1059-941X/07

doi: $10.1111 / j .1532-849 X .2007 .00233 . x$ the material's fracture toughness $\left(K_{\mathrm{IC}}\right)$, which is a measure of the resistance to crack propagation under an induced tensile stress. ${ }^{3}$ Crystal population density is one of the major microstructural parameters generally correlated with strength and $K_{\mathrm{IC}}$ of porcelains and glass-ceramics. ${ }^{4-7}$

A controlled two-stage nucleation and crystallization process is often used to produce a desired volume fraction of crystal phase in a glass body that is self-nucleating or that contains a nucleating agent. ${ }^{8-10}$ During the processing cycle, crystals grow within the glass matrix, and the glassceramic generally becomes stronger and tougher. The improved mechanical properties are associated with the interruption of crack propagation by crystals. In the heat treatment cycle, isothermal holding stages are often used to optimize the 
crystal structure that develops through molecular rearrangements. ${ }^{10}$

The extent and efficiency of crystal formation and growth within the glass matrix are governed by temperature and time factors because of the dynamic nature of crystal growth. ${ }^{1-17}$ The crystal volume usually increases with an increase in temperature and holding time; however, the crystals formed can be dissolved back into the glass matrix under certain conditions of temperature and time. ${ }^{8}$ Thus, as temperature and time increase above the maximum growth conditions, the crystal density may also be reduced. Identification of the unique and optimal range of temperature and time for the heat treatment of certain glasses is critically important for the development of an optimal distribution of crystals. This effectiveness of crystallization can be visualized by plotting $K_{\mathrm{IC}}$ as a function of crystal volume fraction $(V \mathrm{c}) .^{18}$ Fracture toughness of a glass-ceramic also relates to the crystal aspect ratio, which is obtained by dividing the length by the thickness of cross-section for each crystal. $K_{\text {IC }}$ was found to increase with an increase of the aspect ratio, which enhances crack deflection and crack bridging. ${ }^{11,19-21}$

A fluorcanasite-based $\left(\mathrm{Ca}_{5} \mathrm{Na}_{4} \mathrm{~K}_{2} \mathrm{Si}_{12} \mathrm{O}_{30}[\mathrm{OH}\right.$, $\left.\mathrm{F}_{4}\right]$ ) glass-ceramic exhibits a microstructure of bulk crystal phases and high flexural strength and toughness, suggesting its potential use for dental applications. ${ }^{1-13,22,23}$ It is nucleated directly by precipitation of calcium fluoride inherent in its composition, and the principal crystal phases of canasite and fluorcanasite are formed by heterogeneous nucleation on the primary fluoride crystals. ${ }^{11,12}$ Previous studies have reported a positive relationship between fracture toughness and crystal volume fraction; ${ }^{7,13}$ however, the relation can vary depending on the composition of glassceramic, crystallization temperature, and isothermal holding time.

The objective of this study was to determine an effective heat treatment cycle and to test the hypothesis that the change in fracture toughness of a fluorcanasite-based glass-ceramic is a linear function of crystal volume fraction.

\section{Materials and Methods}

A glass cylinder (Corning Glass Works, Inc., Corning, NY) consisting of $2.0 \mathrm{wt} \% \mathrm{Al}_{2} \mathrm{O}_{3}, 16.5 \mathrm{wt} \% \mathrm{CaO}, 7.2$ $\mathrm{wt} \% \mathrm{CaF}_{2}, 9.0 \mathrm{wt} \% \mathrm{~K}_{2} \mathrm{O}, 8.1 \mathrm{wt} \% \mathrm{Na}_{2} \mathrm{O}$, and $57.2 \mathrm{wt} \%$
$\mathrm{SiO}_{2}$ was cut to produce 60 specimen bars, $20 \times 5 \times 2$ $\mathrm{mm}^{3}$. They were mounted and polished, starting with a $45 \mu \mathrm{m}$ diamond-coated disk and finished with 1200 grit $\mathrm{SiC}$ abrasive. The edges of the bar were rounded to minimize stress concentration effects, and the prepared bar specimens were randomly divided into six groups of 10 specimens each.

For the groups tested, crystal nucleation was induced as follows: (i) heating at a rate of $9.2^{\circ} \mathrm{C} / \mathrm{min}$ from room temperature to $550^{\circ} \mathrm{C}$ and holding for 1 hour; and (ii) heating at a rate of $1.5^{\circ} \mathrm{C} / \mathrm{min}$ to $680^{\circ} \mathrm{C}$ and holding for 4 hours in an oven (Furnace 1500, Thermolyne, Inc., Conroe, TX). ${ }^{11}$ Nucleation temperature $680^{\circ} \mathrm{C}$ was chosen based on the soft temperature of glass by differential thermal analysis. ${ }^{24}$ Second stage crystallization treatment was performed as follows: Group 1: $850^{\circ} \mathrm{C}$ for 0.5 hour, Group 2: $850^{\circ} \mathrm{C}$ for 1 hour, Group 3: $850^{\circ} \mathrm{C}$ for 3 hours, Group 4: $750^{\circ} \mathrm{C}$ for 6 hours, Group 5: $800^{\circ} \mathrm{C}$ for 6 hours, and Group 6: $850^{\circ} \mathrm{C}$ for 6 hours. The rate of heat increase was $5.5^{\circ} \mathrm{C} / \mathrm{min}$ from $680^{\circ} \mathrm{C}$ to $850^{\circ} \mathrm{C}$, and each of the specimens was cooled at a rate of $4.6^{\circ} \mathrm{C} / \mathrm{min}$ to room temperature. ${ }^{24}$

After completing the heat treatment, the bar specimens were slowly cooled in the oven to room temperature, and then indented on a specimen surface at an applied load of $9.8 \mathrm{~N}$ using a Vickers microhardness indenter (Model MO 1638, Tukon Microhardness tester, Wilson Instruments, Binghampton, NY). Prior to loading, the indenter was aligned at a right angle to the long axis of each specimen to produce a surface precrack in the center of the polished surface.

After the indentations were produced, specimens were subjected to three-point flexure in ambient air at a relative humidity of $55 \%$, and the flexural strength was calculated using equation (1) (below). The bar specimens were aligned in a self-aligning flexure test fixture with a span length of $19.5 \mathrm{~mm}$. The indented side of each specimen was placed under tension during loading with the indentation diagonal parallel to the tensile stress direction. Bending tests were performed under ambient environmental conditions using a universal testing machine (Model 5500R, Instron Corp., Canton, MA) at a crosshead speed of $0.5 \mathrm{~mm} / \mathrm{min}$

Stress values $\left(\sigma_{\mathrm{f}}\right)$ at failure for the bar specimens were calculated as follows:

$\sigma_{\mathrm{f}}=3 W L / 2 b t^{2}$

where $W$ is the fracture load, $L$ is the test span, $b$ is the specimen width, and $t$ is the specimen thickness.

Fracture toughness $\left(K_{\mathrm{IC}}\right)$ for the bars precracked by a Vickers indenter was calculated according to the following equation:

$\mathrm{K}_{\mathrm{IC}}=\eta(E / H)^{1 / 8}\left(\sigma_{\mathrm{f}} P^{1 / 3}\right)^{3 / 4}$ 
where $\eta$ is a dimensionless constant, $E$ is the elastic modulus, $H$ is the hardness, $P$ is the indentation load, and $\sigma_{\mathrm{f}}$ is stress value.

The $E / H$ values were obtained from measurements of the $b / a$ ratio ( $a$ and $b$ are the diagonal dimensions of the Knoop indentation). ${ }^{26}$ Three measurements were made on each of five randomly selected bar specimens per group subjected to a load of $14.7 \mathrm{~N}$ for a residence time of 30 seconds followed by rapid load removal. The $b / a$ ratio for each measurement was determined, and an average value per group was used in equation (2).

Scanning electron microscopy (SEM, Model JSM6400, JEOL Ltd., Tokyo, Japan) was used to record images of the crystal phase distribution for each of six specimens per group of glass-ceramics. One surface of the bar specimens was polished, etched with $5 \% \mathrm{HF}$ for 1 to 2 seconds, ${ }^{11}$ and coated with a thin layer of goldpalladium alloy. Photographs of the etched surfaces of the glass-ceramic specimens were examined at three randomly selected locations for microstructural observations using SEM. The volume fraction of the crystal phase $\left(V_{\mathrm{c}}\right)$ was calculated by dividing the total number of intersection points lying in the crystal phase by the total number of intersection point areas of crystals by the area sampled on the SEM images. ${ }^{18}$

ANOVA was performed to determine whether differences in means for each group were statistically significant $(p \leq 0.05)$. Duncan's multiple comparison test $(\alpha$ $=0.05)$ was performed to identify the statistical subsets for fracture toughness and crystal volume fraction.

\section{Results}

The mean values and standard deviations of flexural strength, fracture toughness, and crystal volume fraction are summarized in Table 1. ANOVA revealed statistically significant differences between the mean values of the three variables in the glass-ceramic as a function of crystallization temperature and holding time $(p \leq 0.0001)$. Duncan's multiple comparison analysis $(\alpha=0.05)$ revealed five statistical subsets as follows: Group 1, Groups 2/4, Group 3, Group 5, and Group 6. Although most test groups yielded statistically significant differences between groups, the group subjected to $850^{\circ} \mathrm{C}$ for 1 hour yielded similar values in $K_{\mathrm{IC}}$ and $V_{\text {c }}$ compared with a group subjected to $750^{\circ} \mathrm{C}$ for 6 hours. The lowest value was associated with the group crystallized at $850^{\circ} \mathrm{C}$ for 0.5 hour, and the highest value occurred in the group crystallized at $850^{\circ} \mathrm{C}$ for 6 hours.

The mean crystal volume fraction of fluorcanasite crystals ranged from $37 \%$ to $71 \%$. The values were also grouped into five statistical subsets as follows: Group 1, Groups 2/4, Group 3, Group 5, and Group 6 (Duncan's test analysis; $\alpha=0.05$ ). Fracture toughness increased linearly with an increase in crystal volume fraction (Correlation coefficient $\left.\mathrm{R}^{2}=0.67\right)$. The fracture toughness increased by $45 \%$ when the crystal volume fraction increased by $92 \%$.

SEM images of the fluorcanasite glass-ceramic microstructure are shown in Figure 1. A relatively small area of crystal volume fraction was sparsely distributed in a specimen subjected to a crystallization heat treatment at $850^{\circ} \mathrm{C}$ for 0.5 hour (Fig 1A). After heating at $850^{\circ} \mathrm{C}$ for 6 hours, the crystals grew into a rectangular shape with a size distribution of 1 to $3 \mu \mathrm{m}$, and they were distributed more homogeneously in the glassy matrix of the ceramic (Fig 1B). The crystal distribution and concentration in the other groups were intermediate to those of Groups 1 and 6.

\section{Discussion}

The clinical success of a ceramic prosthesis depends to a great extent on its microstructural features and physical strength. ${ }^{1-4}$ This study

Table 1. Means and Standard Deviations (SD) of Flexural Strength, Fracture Toughness $\left(K_{\text {IC }}\right)$, and Crystal Volume Fraction of a Fluorcanasite Glass-Ceramic

\begin{tabular}{|c|c|c|c|c|c|}
\hline Group & Heat Treatment & $\begin{array}{l}\text { Flexural Strength } \\
\quad(S D)(M P a)\end{array}$ & $\begin{array}{c}K_{I C}(S D) \\
\left(M P a \bullet m^{1 / 2}\right)\end{array}$ & $\begin{array}{l}\text { Crystal Volume } \\
\quad(S D)(\%)\end{array}$ & $\begin{array}{c}\text { Duncan's Test } \\
\text { Subsets }\end{array}$ \\
\hline 1 & $850^{\circ} \mathrm{C} / 0.5 \mathrm{hr}$ & $221.9(14.4)$ & $2.7(0.2)$ & $37(3.4)$ & A \\
\hline 2 & $850^{\circ} \mathrm{C} / 1.0 \mathrm{hr}$ & $240.9(13.1)$ & $3.0(0.1)$ & $44(4.2)$ & $\mathrm{B}$ \\
\hline 3 & $850^{\circ} \mathrm{C} / 3.0 \mathrm{hr}$ & $272.0(23.6)$ & $3.3(0.2)$ & $52(4.4)$ & $\mathrm{C}$ \\
\hline 4 & $750^{\circ} \mathrm{C} / 6.0 \mathrm{hr}$ & $232.2(17.9)$ & $3.0(0.2)$ & $45(4.1)$ & B \\
\hline 5 & $800^{\circ} \mathrm{C} / 6.0 \mathrm{hr}$ & $308.5(23.8)$ & $3.7(0.2)$ & $63(5.0)$ & $\mathrm{D}$ \\
\hline 6 & $850^{\circ} \mathrm{C} / 6.0 \mathrm{hr}$ & $319.7(15.1)$ & $3.9(0.2)$ & $71(5.7)$ & $\mathrm{E}$ \\
\hline
\end{tabular}




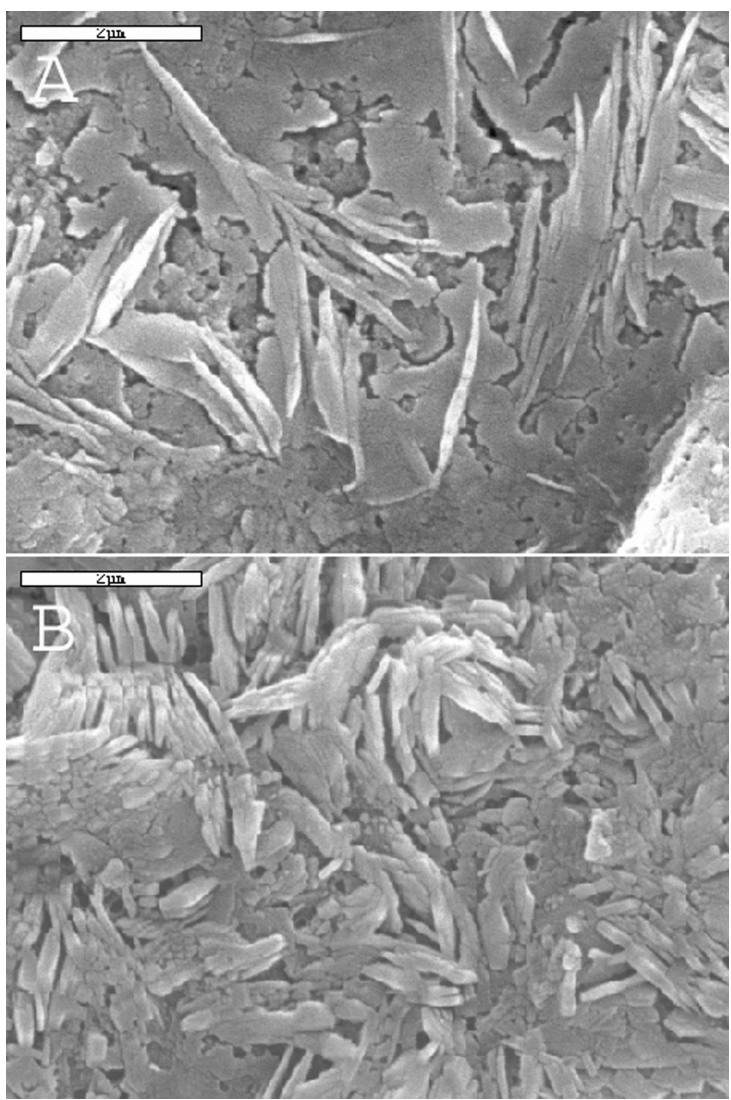

Figure 1. SEM images of fluorcanasite crystals for two combinations of crystallization temperature and isothermal holding time. The crystal volume fraction increased from $37 \%$ for $850^{\circ} \mathrm{C} / 0.5 \mathrm{hr}$ (A) to $71 \%$ for $850^{\circ} \mathrm{C} / 6 \mathrm{hr}(\mathrm{B})$. Length of the measurement bars: $2 \mu \mathrm{m}$.

was designed to determine the effect of heat treatment on the crystal volume fraction and fracture toughness of a fluorcanasite $\left(\mathrm{Ca}_{5}\right.$ $\mathrm{Na}_{4} \mathrm{~K}_{2} \mathrm{Si}_{12} \mathrm{O}_{30}\left[\mathrm{OH}, \mathrm{F}_{4}\right]$ ) glass-ceramic using a conventional two-stage heat treatment. ${ }^{11}$ For all specimens, the nucleation heat treatment schedule was held constant at $680^{\circ} \mathrm{C}$ for 4 hours based on results from our previous study. ${ }^{13}$ As ceramics start to lose translucency and become more opaque beyond the glass transition temperature $\left(T_{\mathrm{g}}\right)$, investigation of crystallization temperature was performed over the range of $750-850^{\circ} \mathrm{C}$. The $T_{\mathrm{g}}$ of fluorcanasite glass-ceramic is approximately $810^{\circ} \mathrm{C}^{10,11}$

The fracture toughness and crystal volume fraction increase with an increase in heat treatment temperature and time of crystallization growth. ${ }^{4,5,10,13}$ In the present study, the mean fracture toughness and crystal volume fraction also increased significantly with an increase of crystallization temperature from 750 to $850^{\circ} \mathrm{C}$ and isothermal holding time from 0.5 to 6 hours (Table 1). Dissolution of crystals back into glass matrix $^{8}$ was not observed in the current investigation. The relatively lower value of fracture toughness of the specimens heated to $850^{\circ} \mathrm{C}$ for 0.5 hour $\left(2.7 \mathrm{MPa}^{1 / 2}\right)$ was associated with a lower percent of crystallinity by volume (37\%). The higher value of fracture toughness of specimens heated to $850^{\circ} \mathrm{C}$ for 6 hours $\left(3.9 \mathrm{MPa} \bullet \mathrm{m}^{1 / 2}\right)$ was associated with a higher percent of crystallinity by volume $(71 \%)$. These results support the critical role of crystals in impeding further crack propagation in ceramics through a crack deflection mechanism. ${ }^{5,6}$

The superior fracture toughness with heat treatment might also result from the increased crystal aspect ratio. Experimental studies showed an impact of the aspect ratio of various particle morphologies on $K_{\text {IC, }}$, where $K_{\text {IC }}$ increased with an increase of the aspect ratio, and vice versa. ${ }^{11,19-21}$ Fracture toughness increased monotonically with aspect ratio in a series of hot-pressed silicone nitride compositions. ${ }^{19}$ The observed quantitative increase in $K_{\mathrm{IC}}$ with high aspect ratio crystals results from crack deflection and crack bridging in glass-ceramics. ${ }^{20,21}$

No statistically significant difference was found in fracture toughness and crystal volume fraction between Groups $2\left(850^{\circ} \mathrm{C} / 1 \mathrm{hr}\right)$ and $4\left(750^{\circ} \mathrm{C} / 6\right.$ $\mathrm{hr})$. Similar microstructure and fracture toughness of fluorcanasite glass-ceramic were obtained by increasing the crystallization temperature from 750 to $850^{\circ} \mathrm{C}$ for a significantly shorter thermal processing time. Thus, an optimal schedule for thermal processing should be balanced with a refined control of crystallization temperature and isothermal holding time. Proper nucleation conditions are also essential to ensure the formation of numerous nucleation sites and a homogenous distribution pattern of crystals for an optimal dental prosthesis. ${ }^{5,13}$

Fracture toughness increased linearly as a function of crystal volume fraction. Within the range of crystal volume fraction (35-71\%), the relationship between fracture toughness and crystal volume fraction of a fluorcanasite glass-ceramic can be expressed as follows:

$K_{\mathrm{C}}=2.61+0.0353 V_{\mathrm{c}}$ 
where $K_{\mathrm{C}}$ is the fracture toughness, and $V_{\mathrm{c}}$ is the crystal volume fraction.

Glass-ceramic microstructures are associated with crystallization rates of glass-ceramics that occur by ionic transport at the interface between the nuclei and the surrounding glass matrix..$^{8,14,17}$ The heat treatment creates entropy changes that drive kinetic and morphological processes at the interfaces toward crystal growth. ${ }^{10,11}$ The thermodynamic properties of the glass-ceramic during crystallization control the formation of the crystal phase and the subsequent toughening of the structure. ${ }^{8,16}$ Ionic diffusion at the interface in the fluorcanasite glass-ceramic is very sensitive to the heat treatment process. ${ }^{10-11}$

The distribution pattern of crystals in the fluorcanasite glass-ceramic was more homogeneous in the specimens heated at $850^{\circ} \mathrm{C}$ for 6 hours than the specimens heated at $850^{\circ} \mathrm{C}$ for 0.5 hour (Fig 1). The crystals appear elongated and spindly, sporadically clustered, and arranged in linear patterns in the specimens heated at $850^{\circ} \mathrm{C}$ for 0.5 hour (Fig 1A). As crystallization temperature/holding time increased to $850^{\circ} \mathrm{C} / 6 \mathrm{hr}$, the crystals transformed into rectangular interconnected shapes and were distributed more homogeneously throughout the glassy matrix. The crystal boundaries also were more distinctly delineated, and the crystals formed aggregates, yielding a hierachical structure of fluorcanasite (Fig 1B), with an associated increase in fracture toughness. ${ }^{27}$

The anisotropic growth of crystals is typical for fluorcanasite glass-ceramics. ${ }^{12,17,22,23}$ During the controlled crystallization process, microcrystals were formed as heterogeneous nuclei, a typical mechanism for most glass-ceramics. ${ }^{8,17}$ Fluorcanasite crystals grew with further heat treatment to form a uniformly dense network of interlocking crystals throughout the glassy matrix (Fig 1B); however, these crystals grew preferentially along one crystallographic axis of needle-like crystals. This process may develop considerable stress around the crystals during crystallization, and the stress may cause microcrack formation on cooling within the glass phase area of the microstructure of the glass-ceramic $;{ }^{17}$ however, the dense interlocking microstructure of crystals prevents microcracks from propagating further, and this process results in considerably greater fracture toughness. ${ }^{3,5,11}$
The present study was limited to a crystallization temperature range of $750-850^{\circ} \mathrm{C}$ and an isothermal holding time of $0.5-6 \mathrm{hr}$. The optimization of heat treatment needs further investigation to develop the maximum crystal volume fraction in the shortest amount of processing time.

\section{Conclusions}

Within the limitations of this study, it was determined that the increase in fracture toughness of a fluorcanasite glass-ceramic occurred as a linear function of crystal volume fraction within a crystallization temperature range of $750-850^{\circ} \mathrm{C}$ and an isothermal holding time ranging from 0.5 to 6 hours. More homogeneous crystal patterns can be obtained under an optimal balance between crystallization temperature and isothermal holding time for a fluorcanasite glass-ceramic.

\section{References}

1. MacGulloch WT: Advances in dental ceramic. Br Dent J 1968;124:361-365

2. Kingery WD, Bowen HK, Uhlmann DR: Introduction to Ceramics (ed 2). New York, NY, John Wiley, 1976, pp. 368-374

3. Callister WD Jr: Materials Science and Engineering. An Introduction (ed 4). New York, NY, John Wiley, 1997, pp. 399-401

4. Dong JK, Luthy H, Wohlwend A, et al: Heat-pressed ceramics: technology and strength. Int J Prosthodont 1992;5: 9-16

5. Kon M, Kawano F, Tada Y, et al: Effect of crystallization on fracture strength of castable glass-ceramics containing two crystals. Dent Mater J 1994;13:47-54

6. Tada Y, Kawano F, Kon M, et al: Influence of crystallization on strength and color of castable glass-ceramics containing two crystals. Biomed Mater Eng 1995;5:233-243

7. Anusavice KJ, Zhang NZ: Effect of crystallinity on strength and fracture toughness of Li2O-Al2O3-CaO-SiO2 glassceramics. J Am Ceram Soc 1997;80:1353-1358

8. Kelton KF: Crystal nucleation in liquids and glasses. Solid State Phys, 1991;45:75-77

9. Weinberg MC: Interpretation of DTA experiments used for crystal nucleation rate determinations. J Am Ceram Soc 1991;74:1905-1909

10. Parsell DE, Anusavice KJ: Optimization of glass-ceramic crystallization based on DTA exotherm analysis. Dent Mater 1994;10:167-171

11. Zhang NZ, Anusavice KJ: Effect of alumina on the strength, fracture toughness, and crystal structure of fluorcanasite glass-ceramic. J Am Ceram Soc 1999;82:25092513

12. Beall GH: Chain silicate glass ceramics. J Am Non-Cryst Solids 1991;129:163-173 
13. Oh WS, Zhang NZ, Anusavice KJ: Effect of nucleation temperature on fracture toughness (KIC) of fluorcanasitebased glass-ceramic. Int J Prosthodont 2003;16:505-509

14. Gorman GM, Hill RG: Heat-pressed ionomer glassceramics. Part I: an investigation of flow and microstructure. Dent Mater 2003;19:320-326

15. Johnson A, Shareef MY, van Noort R, et al: Effect of furnace type and ceramming heat treatment conditions on the biaxial flexural strength of a canasite glass-ceramic. Dent Mater 2000;16:280-284

16. Johnson A, Shareef MY, Walsh JM, et al: The effect of casting conditions on the biaxial flexural strength of glassceramic materials. Dent Mater 1998;14:412-416

17. Höland W, Beall G: Glass-Ceramic Technology. Westerville, OH, The American Ceramic Society, 2002, pp. 57-74

18. DeHoff RT, Rhines FN: Quantitative Microscopy. New York, NY, McGraw-Hill, 1968, pp. 336-339

19. Faber KT, Evans AG: Grack deflection process - II, Experiment. Acta Metall 1983;31:577-584

20. Baik DS, No KS, Chun SS: Mechanical properties of mica glass-ceramics. J Am Ceram Soc 1995;78:1217-1222
21. Hill YJ, Mecholsky JJ, Anusavice KJ: Fractal analysis of toughening behavior in $3 \mathrm{BaO} \cdot 5 \mathrm{SiO} 2$ glass-ceramics. J Am Ceram Soc 2000;83:545-552

22. Dorfman MD, Rogachev DD, Goroshchenko ZI, et al: New Minerals, Canasite. Am Mineral 1960;45:253-254

23. Chiragov MI, Mamedov KHS, Belov ANV: Crystal structure of canasite, Ca5Na4K2[Si12O30](OH, F4). Dokl Akad Nauk SSSR 1969;185:96-99

24. Anusavice KJ, Zhang NZ: Effect of nucleation temperature on toughness and flexure strength of canasite glassceramics. J Dent Res 1996;75:67 (IADR Abs. No. 395).

25. Chantikul P, Anstis GR, Lawn BR, et al: A critical evaluation of indentation techniques for measuring fracture toughness: II. Strength method. J Am Ceram Soc 1989;64:539-543

26. Marshall DB, Noma T, Evans AG: A simple method for determining elastic-modulus-to-hardness ratios using Knoop indentation measurements. J Am Ceram Soc 1982;65:G175-C176

27. Lakes R: Materials with structural hierarchy. Nature 1993;361:511-515 